\title{
Nurse managers' visions of future challenges in health care organizations
}

\author{
Reetta Saarnio ${ }^{1 *}$, Marjo Suhonen ${ }^{2,3}$ and Arja Isola ${ }^{2}$
}

*Correspondence: reetta.saarnio@gmail.com



${ }^{1}$ Helsinki Metropolia University of Applied Sciences, Helsinki, Finland.

${ }^{2}$ Research Unit of Nursing Science and Health Management, University of Oulu, Oulu, Finland.

${ }^{3}$ Medical Research Center Oulu (MRC Oulu), Finland.

\begin{abstract}
Background: Because of the economic crisis and nursing shortage, the situation for hospitals will be demanding throughout the decade in the 2010s. This poses challenges for nursing management. This article focuses on Finnish health care, particularly on nurse managers.

Aim: The aim of this study is to describe and analyse future challenges in hospitals in one hospital district in Finland from the viewpoint of the nurse managers. The research question for this study is as follows: What kinds of future challenges are there in one hospital district from the viewpoint of the nurse managers?

Method: The data was collected in the year 2011 from a number of essays $(n=60)$ written by front-line and mid-level nurse managers in one hospital district. The data was analysed using a qualitative content analysis.

Findings: Nurse managers saw challenges and threats for the future on the level of society, the hospital, the work unitand for employees. Work-unit level challenges were emphasized in these findings.

Conclusion: The study shows that nurse managers have the ability to identify challenges in the future that they can influence by carrying out change management procedures. There is a need for more holistic management and closer interprofessional co-operation in health care for the benefit of patients in terms of customer oriented care. Furthermore, shared leadership is needed, which on a work-unit level means better pair management involving a front-line nurse manager and a physician. One requirement for nurse managers is the need to develop a sense of community. The ability to create environments that promote staff well-being is also important from the viewpoint of staff turnover. Nurse managers are usually well educated, so they should make more of an effort to utilize their education in their management work and update their expertise in management matters as well.
\end{abstract}

Keywords: Nursing management, future, challenges, hospitals

\section{Background}

The situation in health care organizations in the 2010s is challenging, due to factors such as nursing shortages [1], problems related to creating healthy working environments [2], the economic recession and problems in recruiting leaders [3]. These changes pose challenges for delivering high-quality patient care and ensuring a good standard of customer orientation. The adequacy of the managerial skills of nurse managers is an essential issue in responding to these questions [4].

This article focuses on Finnish health care, particularly on nurse managers. In this article 'nurse managers' refers both to front-line and mid-level nurse managers. The front-line manag- ers' most important mission is to support staff in taking care of the basic tasks in the work unit by creating the best conditions for carrying out high-quality nursing [5]. 'Mid-level managers' set the pace for executing strategic plans and focus on the organization's priorities [6]. The Finnish system is the focus of this study because in recent years health care reforms have been more the rule than the exception in the Nordic countries [7]. As a result of the recent Health Care Act [8] citizens in Finland now have greater opportunities to choose their health care facility and their health care professionals. The patients' role in the planning and implementation of their own care is also emphasized more than before. 
Saarnio et al. Journal of Nursing 2016,

The Finnish health care system consists of primary health care services and specialised medical care services. Primary health care services are arranged for citizens by their own municipalities and offered in health centres and central hospitals. Specialised medical care services are arranged for citizens by municipalities that form a hospital district and are mainly offered in hospitals. Patients first visit basic health care services, from where they are referred by physicians to specialised medical care services if necessary [8].

According to the extensive NEXT study, carried out in a number of European countries, one in three Finnish nurses who participated in a large longitudinal study were included in the group with the most adverse levels of job strain [9]. The future challenges facing hospitals in Finland need to be explored from the viewpoint of nurse managers.

Change management is an essential means to respond to future challenges [10]; however, there are few studies examining nurse managers' experiences of change. Change management in our article refers to the process of renewing an organization's direction, structure, and capabilities to serve the needs of external and internal customers' [11]. Managers find organizational changes difficult to manage [12]. Below we present the priorities in change management for the future from the viewpoint of nurse managers based on prior studies.

The first priority is that shared leadership will be empha- sized in the future. Shared leadership means that managers represent different professions and changes are managed so that there is true collaboration between groups with mutually complementary skills [13]. The second focus is on interprofessional collaboration, which means that different professional groups work together combining fields of know-how effectively for the benefit of the patient. Taking on the role of a clinical nurse leader is an innovative opportunity to conduct interprofessional collaboration [14]. The third priority is creating and maintaining healthy working environments and ensuring nurses' job satisfaction. Generating awareness of and commitment to the organizational missions are important in this [15].

\section{Methods}

Aim

This article focuses on nurse managers in hospitals in a Finnish hospital district which provides specialised medical care services. The aim of the article is to describe and analyse future challenges in hospitals in one hospital district in Finland from the viewpoint of nurse managers. Our research question is as follows: What kinds offuture challenges are there in one hospital district from the viewpoint of nurse managers?

\section{Data collection}

We describe the study design in Figure 1. This study is part




of a larger study whose aim was to analyse visions of the future of one hospital district from the viewpoint of head nurses and nursing directors [16]. The data was collected in 2011 from essays $(n=60)$ during a training and development session aimed at nurse managers ina hospital district. Before handing out the question for the essay, the main principles and aims of the study where explained to the participants. Twenty minutes was reserved for the writing.

The participants were front-line nurse managers $(n=48)$ and mid-level nurse managers $(n=9)$. Three participants did not reveal their position. Sixteen of the front-line managers had a Master's degree and three had a Bachelor's degree in Health Sciences. Six mid-level nurse managers had a Master's degree in Health Sciences. The majority of the participants were working as front-line managers, and a few as mid-level nurse managers. Twenty minutes was reserved for the writing according to procedures adopted previously in earlier studies $[\mathbf{1 7}, \mathbf{1 8}]$.

\section{Data analysis}

The data was analysed using an inductive content analysis method [19]. In the first phase, two researchers read through the data several times. The analysis process progressed by searching the data for statements referring to the future of the hospital district, especially regarding how things had progressed towards that future vision. An entity consisting of one or several sentences was chosen as the unit of analysis [20].

The statements found were organized into categories based on similarities and differences. The aim was to retain the ter- minology of the original data when forming the categories. At this stage, the researchers used theirown judgement and decided which matters to place in the same category [20]. To control the consistency of the interpretations, subcategories were compared once more with the original text. Each subcategory was given a name describing its contents.

Finally, head categories were produced from the subcategories, and main categories from these, using continuous comparison. In the following table we present an example of the data analysis process (Table 1). In the text, four main categories each with a number of head categories were identified and formulated. The main categories were as follows: society level, hospital level, work unit level and employee level. Consequently, as a result of the content analysis, the future challenges from the viewpoint of nurse managers were formulated.

\section{Ethical considerations}

According to Finnish regulations, review by an ethical committee was not necessary since the study involved only staff. An application for permission to carry out the study was made to the director of nursing. Before data collection, the researchers informed the nurse managers that participating in the study was voluntary and that the answers would be handled confidentially. To ensurethe informants' anonymity and privacy only the age, education and work experience in nurse management were gathered as base information [21]. There were 123 informants in the study as a whole, but this part of study had 60 informants, making it impossible to

Table 1. Condensed example of the abstraction and organisation of data when forming the main category: "Work unit level challenges".

\begin{tabular}{|c|c|c|c|c|}
\hline Original statement from the material & Abstracted statement & Subcategory & Headcategory & Maincategory \\
\hline $\begin{array}{l}\text { "Fragmented and physician- oriented } \\
\text { management" }\end{array}$ & Physician- oriented & \multirow[t]{2}{*}{$\begin{array}{l}\text { Development of } \\
\text { pair management }\end{array}$} & \multirow{2}{*}{$\begin{array}{l}\text { Front-line } \\
\text { management in } \\
\text { every-day practice }\end{array}$} & \multirow[t]{2}{*}{$\begin{array}{l}\text { Work unit leve } \\
\text { challenges }\end{array}$} \\
\hline $\begin{array}{l}\text { "Although front-line nurse managers } \\
\text { do all they can their work is not } \\
\text { acknowledged and well-being is not } \\
\text { supported" }\end{array}$ & $\begin{array}{l}\text { Challenges in a front-line nurse } \\
\text { manager's work }\end{array}$ & & & \\
\hline $\begin{array}{l}\text { "Staff members have not been able to } \\
\text { influence their own issues in the work } \\
\text { unit" }\end{array}$ & $\begin{array}{l}\text { Staff cannot influence their own } \\
\text { work }\end{array}$ & $\begin{array}{l}\text { Development of } \\
\text { working conditions } \\
\text { and atmosphere }\end{array}$ & -- & -- \\
\hline $\begin{array}{l}\text { "Nursing staff members are not } \\
\text { valued as experts, only as physicians' } \\
\text { assistants." }\end{array}$ & Nursing and nurses are not valued & -- & -- & -- \\
\hline "People are afraid to speak out" & A discussion culture is missing & -- & -- & -- \\
\hline $\begin{array}{l}\text { "Not enough attention has been paid to } \\
\text { customer feedback." }\end{array}$ & $\begin{array}{l}\text { Responding to customer feedback } \\
\text { has been neglected }\end{array}$ & $\begin{array}{l}\text { Development of } \\
\text { customer feedback } \\
\text { system }\end{array}$ & -- & -- \\
\hline "Work unit values are not clear." & No shared values in work units & \multirow{3}{*}{$\begin{array}{l}\text { Making the strategy } \\
\text { of work units clearer }\end{array}$} & \multirow[t]{3}{*}{--} & \multirow[t]{3}{*}{--} \\
\hline "The basis of common work is unclear." & No clear strategy in work units & & & \\
\hline $\begin{array}{l}\text { "The staff does not have a clear } \\
\text { understanding of what is expected of } \\
\text { them." }\end{array}$ & Activities are not clearly defined & & & \\
\hline
\end{tabular}


Saarnio et al. Journal of Nursing 2016,

identify individual writers [20].

\section{Trustworthiness of the study}

We ensured the trustworthiness of this study by paying attention to the truth value, applicability, consistency and neutrality [22]. We confirmed the truth value of this study by using a total sampling method and by analysing data as it emerged based on the essays. The data was rich, and almost all of the participants used up a whole side of an A4 sheet of paper and some also wrote on the other side of the paper. We have included quotes from the original data in this article. Applicability (transferability) of the results requires case-specific judgment. The multi-level approach used in this study is applicable in other countries with a high-quality health care system. From the viewpoint of consistency, we have described the research process so that it can be repeated if necessary. We have confirmed neutrality in our study by reflecting on our interpretations of the original data. Furthermore, the original essay material was analysed by two separate researchers.

The study has some limitations. First, one critical point is how well the participants were able to imagine the future and detach themselves from the present. The second limitation is related to the short time given to the participants to write the essay. However, this time (20 minutes) seemed to be of sufficient length because none of the participants asked for more time and a short time of about 20 minuteshas been sufficient according to earlier studies [23].

\section{Results}

This section presents the challenges which came to light a result of this study. The challenges were seen on multiple levels (Figure 1).

\section{Society-level challenges}

The first category in our study was society level changes. Society-level challenges were related to the effects of legislation on practice, challenges related to co-operation between organizations, the difficult economic situation and organizing education. We are now presenting these challenges.

\section{The effects of legislationon practice}

The first society level challenge revealed in this study was that tasks had not been sufficiently clearly specified by legislation. An additional challenge in this respectwas related to the new Health Care Act [8]. Nurse managers were afraid that responsibility for care would become blurred once the new act was adopted, giving voice to a perceived threat that no one would assume overall responsibility for patient care.

"The new health act has proved to be a failure... because in this new law responsibility for care is fragmented, no one has overall responsibility for patient care, people only mind their own business..."

\section{Challenges related co-operation between organizations} Nurse managers saw challenges related to co-operation on different levels. They saw difficulties in co-operation between municipalities as well as in co-operation between basic health care services and specialized health care services. Nurse managers saw problems especially related to the service chainin the flow of information between basic health care services and specialized health care services.

"The graduation of care has proved not to work."

"There are problems in the flow of information concerning patients between hospital and continued care places because the patient information system still does not work."

\section{The difficult economic situation}

Nurse managers saw challenges related to the economy in the future on both national and municipal levels. These challenges included a weaker overall economy, a crisis due to a lower value of the euro and the poor financial situational of municipalities. Furthermore, municipalities had faced challenges in allocating resources for the prevention ofnational diseases, such as diabetes.

"We have no time to do preventive work, and patient education does not also work."

\section{Organizing education}

Nurse managers felt that education especially in advanced studies in nursing, i.e., at polytechnic level, had failed to respond to the changing demands of specialized health care. They felt that the education focuses on irrelevant matters when compared to the reality of nursing work.

"Education in advanced studies in nursing, especially on the polytechnic-level, focuses on irrelevant matters, it has no connection with practical work."

\section{Hospital-level challenges}

The second category in our study was hospital-level changes. Hospital-level challenges were related to use of financial resources, reinforcement of strategic management and staff recruitment and retention. We are now presenting these challenges.

\section{The use of financial resources}

Nurse managers were afraid that the hospital's financial resources had been used in an uncontrolled way: the resources had not been allocated in a relevant manner. They suspected that it was a result of the use of in appropriate criteria in competitive tendering. In addition, nurse managers worried that in hospitals too much money will be spent on hospital premises and that the premises/rooms and instruments may be inappropriate. For example, money spent on information systems was viewed as unplanned. They also worried that there would be no resources for quality work unlike in the private sector.

"The private sector will develop their quality of care... and on the other hand, people can afford and will pay for their care and health care services as well." 
Saarnio et al. Journal of Nursing 2016,

\section{Reinforcement of strategic management}

Reinforcement of strategic management included the visions concerning the future of the hospital district, staff not having a clear picture of their basic mission, and the failure of education to meet work assignments. Nurse managers considered that the challenges facing top-level management were related to failure of the visions concerning the future of the hospital district. This was seen as being due to the fact that the hospital district had been unable to respond to large social problems, such as the aging population. Nurse managers also thought that there were problems associated with drawing up a strategy for the hospital, which was in their opinion completely missing or too abstract, making it difficult to utilize the strategy in practical work. The nurse managers were also afraid that nursing staff did not have a clear picture of their basic mission.

"The strategy for the hospital district and visions about 'a top hospital of the future' do not reach employees at the work units."

"The strategy for the hospital district is not rooted in the practical work of the units."

"The core of nursing has been lost."

"It is important to clarify what the basic idea of nursing is and where it has gone?"

Nurse managers saw the clarification of staff job descriptions and the transfer of tasks between personnel as future management challenges. In their opinions, education and work assignments did not match. The functionality of staff induction had involved challenges, such as lack of planning, which was seen in the insufficient time reserved for induction. As a result, employees' skill levels had deteriorated. As baby boomers had retired, there had been difficulties in transferring their tacit knowledge to younger generations of new health care staff.

"Staff retirement rates are accelerating, but we still have not learned how to transfer tacit knowledge."

\section{Staff recruitment and retention}

Nurse managers considered that the major challenges related to staff recruitment and retention were that experienced and skilful staff had moved on toother workplaces. Nurse managers were also afraid that staff members who had taken leave to take up studies would not return to the hospital, but would transfer to other hospitals.

"There is a brain drain from our hospital to other hospitals."

Nurse managers claimed that nursing staff would no longer commit to permanent employment; instead, they would work through contract recruitment agencies, like physicians. This might lead to a high turn over of staff. Recruitment of staff on a permanent basis had been hampered by a lack of a salary system with incentives, meaning that possibilities for rewarding nurses for good work had been non-existent.

"It would be a better alternative to use a positive attitude and a reward system. If the staff were satisfied, then the pa- tients would also be satisfied..."

\section{Work unit-level challenges}

The third category in our study was work unit-level challenges. The work unit-level challenges were related to customer orientation, inadequate interprofessional co-operation, frontline management in every-day practice, promotion of staff well-being and the development of nursing. We are now presenting the challenges.

\section{Customer orientation as a challenge}

Nurse managers considered it very important to emphasize genuine customer orientation in the future. They saw major changes in the quality and quantities of patients as being challenges related to customer orientation. At the same time the positions of the patients were seen differently: some nurse managers saw patients as active participants in their careand some nurse managers saw patients as not having sufficient expertise to participate and that they had unrealistic expectations regarding their treatment.

"The patients have been given too much power to choose their care... their requirements are sometimes absurd. They will seek out information about treatment on the Internet before they come to the hospital."

"Today patients know more about their treatment than earlier, and that is their right..."

The number of patients was seen as increasing in relation to the number of nurses, and this was seen as an inevitable increase in the workload of the staff. However, nurse managers were also afraid that the new Health Care Act [8] would create a situation where patients go to other hospitals for their treatment. This would cause serious financial difficulties for the hospitaldue to a decline in the number of patients.

\section{Inadequate interprofessional co-operation}

Nurse managers considered that interprofessional co-operation had suffered as a result of competition between various professional groups, mainly nurses and physicians. As a result, customer orientation had suffered because it had been difficult for different professional groups to work together.

"Interprofessional work and co-operation have been lost.... we talk about interprofessional work but I am afraid that not all of us know what it really means, and the staff are not aware of the common goals of work."

"Interprofessional work between nurses and physicians does not work; as a result, the patients are dissatisfied, which is seen in the feedback they give. It does therefore affect the quality of care."

\section{Front-line management in every-day practice}

Nurse managers saw the development of customer feedback systems, shared leadership, achievement of a more clearly defined strategy for work units,as well as the development of working conditions and atmosphere all as challenges related 
Saarnio et al. Journal of Nursing 2016,

to front-line management. Furthermore, nurse managers thought that it was important to increase staff members' opportunities to influence their own work and feel their work to be meaningful.

"Payment increases alone do not motivate people; the work has to be meaningful, and it is important that you can be satisfied with your work performance. It is also important that when nurses go home, they can feel that they have done their work well."

Nurse managers also saw several problems related to the work of front-line managers, such as having great responsibility but little power. In relation to development of strategies in work units, nurse managers saw a need to increase the collective discussion about development plans. It was seen as important that every employee is aware of the aims and values of the work unit.

"As a front-line nurse manager I still have a lot of responsibilities, but no authority."

"Front-line managers think about seeking new job opportunities: there are too many responsibilities and things that need improving, but no resources."

\section{Promotion of staff well-being}

Nurse managers thought that the first step could be utilizing the results of a well-being survey, followed by drawing up a well-being plan for the staff. If necessary, employees should have access to work supervision. In addition, nurse managers saw supporting aging employees and combining work and family life as being important in terms of staff well-being.

"The workplace would be more attractive if the employer focused more attention on the staff's well-being and employee benefits, such as opportunities to exercise."

"It is essential to draw attention to what is most important: the care of patients and the staff who do this work."

\section{Development of nursing}

Nurse managers considered that development of nursing had been unplanned and under-resourced. Moreover, the atmosphere had not been supportive. Nurse managers thought that they had not had any instruments to measure the effectiveness of nursing. They also thought that it would be important to invest in research and evidence-based nursing.

"There is not enough time for development of nursing because all the time is taken up by trying to control the situation... I mean daily management."

\section{Employee-level challenges}

The fourth category in our study was employee-level challenges. Employee-level challenges were related tosupporting nurses' careers and increasing a sense of community.

\section{Supporting nurses' careers}

Nurse managers thought that nurses had not had the opportunity to progress in their careers. They also saw their own opportunities for professional development as being weak. This was seen as a resultas the hospital district had no plans for nurses' professional development.

"Nurses feel that opportunities for their own professional development are weaker in work units in the hospital district than elsewhere because there are no plans for nurses' personal career and professional development."

\section{Increasing a sense of community}

In relation to a sense of community, nurse managers considered that it was important to develop staff member's workplace skills. Nurse managers saw that it was easy extinguish the sense of community if the rules at the hospital were too inflexible or strict. They also thought that employees' individuality had been supported too much, leading to a loss of a sense of community in a work unit.

"Individuality has assumed too big a role here... so big that everyone thinks only of their own benefit and just works based on this principle. The sense of community and the employees' desire to work together has been extinguished because of rules that are too strict and inflexible."

\section{Discussion and conclusions}

In this section we will discuss the findings of the study and attempt to draw some conclusions regarding to Nurse managers' visions of future challenges in health care organizations. Nurse managers saw challenges, even threats, in the future on all the levels outlined in the findings (Figure 1). We consider it is positive that nurse managers saw challenges on different levels, because it shows that nurse managers have the ability to identify issues that they can influence by carrying out change management. However, change management is demanding managerial work $[10,12]$.

The challenges that the Finnish nurse managers identified seem to be quite similar compared to the previous studies, where nursing shortages, staff well being and interprofessional collaboration were also discussed $[1,3,14,15]$. An interesting viewpoint related to Finnish health care is that the legislation has been renewed at a fast pace and it requires nurse managers to adopt new kinds of working methods and leadtheir work units through a continuous change process in order to promote and implement things such ascustomer orientation for example.

The results show a need for more holistic management and closer co-operation between professions in health care. In this kind of situation nurse managers need managerial education and training. Certain leadership skills are needed when supporting staff through changes [5,9]. Long term and continuing leadership should work to develop the working conditions and atmosphere in work units. Maintaining the awareness of a units' vision and mission arealso essential issues in change management [11]. The need to strengthen these workings was seen in the results. The ability to create environments that promote staff wellbeing is also important 
Saarnio et al. Journal of Nursing 2016,

from the viewpoint of staff turnover [9]. At the same time, it is important to remember that the atmosphere of a work unit is also the responsibility of the whole work community, not onlythe nurse managers.

Still nurse managers' ability to identify leadership work related to promoting good working conditions and maintaining awareness of the missionis highly important in their management work and allocating time for this work is essential. If the nurse manager does not recognize these issues as an essential part of the job, or a nurse manager recognizes a knowledge gap related to these issues, she/he should have the option to have more education and training in nursing management $[4,5]$. Nurse managers usually have a high-level of education so they should make more efforts to utilize it in their management work and update their expertise in management as well.

One requirement for nurse managers is the need to develop a sense of community. Individual employees need to gain a stronger sense of community, and this has to be promoted by the whole work unit. These issues are a question of a long-term process related to organizational culture change. Previous studies have also emphasized the importance of a new kind of thinking and change management among nurse managers and a need to recognize their own opportunities in change management $[7,26]$.

When looking at interprofessional co-operation, nurse managers need to make more efforts to promote interprofessional co-operation and take a leadership role, for example, in teams and in work units. Previous studies claim that nurses do not traditionally have leadership roles in interprofessional teams [24]. When fulfilling requirements for more customer oriented care, well working co-operation between professions is essential. Increased, shared leadership is needed. On the work unit level this means pair management involving a front-line nurse manager and a physician. We assume that difficulties in co-operation may be a sign of mistrust. However, trust is required between nurses and physicians so that they can lead their staff through changes together $[13,24]$. It is also important to maintain discussion and to set objectives together. It is important that both nurses and physicians see the benefits of cooperation; otherwise, shared leadership will not be possible. The role of the clinical nurse leader also provides an opportunity to find a solution [15].

Furthermore, unplanned and un-resourced nursing development was seen as a major future challenge on the work unit level. Development of evidence-based practice is one example of this [14]. An unsupportive atmosphere in this respect is one challenge in this area. Nursing development work is under the nurse managers' authority and they can influence the resources used in the work, how it is planned and how it relates to daily nursing work. Nurse managers may see development work as being partially separate from daily nursing. Creating a positive atmosphere in development work is the nurse manager's task as well.

We conclude that from the viewpoint of nurse managers, health care organizations will face large and complex challenges in the future. Managing them successfully does not only require empowered nurse managers who stay working in their organizations and have skills and competencies required [26]. It also requires support from other managers and employees and well-working co-operation with other professions groups for the benefit of the patients.

\section{Competing interests}

The authors declare that they have no competing interests.

Authors' contributions

\begin{tabular}{|l|c|c|c|}
\hline Authors' contributions & RS & MS & AI \\
\hline Research concept and design & $\checkmark$ & $\checkmark$ & $\checkmark$ \\
\hline Collection and/or assembly of data & $\checkmark$ & -- & $\checkmark$ \\
\hline Data analysis and interpretation & $\checkmark$ & $\checkmark$ & $\checkmark$ \\
\hline Writing the article & $\checkmark$ & $\checkmark$ & $\checkmark$ \\
\hline Critical revision of the article & $\checkmark$ & $\checkmark$ & -- \\
\hline Final approval of article & -- & $\checkmark$ & -- \\
\hline Statistical analysis & -- & -- & -- \\
\hline
\end{tabular}

Acknowledgement and funding

Gary Attwood, AAC Global.

Publication history

Editor: Chong-Chi Chiu, Chi Mei Medical Center, Taiwan.

Received: 10-Dec-2015 Final Revised: 21-Jan-2016

Accepted: 08-Feb-2016 Published: 16-Feb-2016

\section{References}

1. Dotson MJ, Dave DS and Cazier JA. Addressing the nursing shortage: a critical health care issue. Health Mark Q. 2012; 29:311-28. | Article | PubMed

2. Dhondt S, Delano P F and O. Kraan K. The importance of organizational level decision latitude for well-being and organizational commitment. Team Performance Manag. 2014; 20:307-327. I Article

3. Alameddine $M$, Baumann A, Laporte A and Deber R. A narrative review on the effect of economic downturns on the nursing labour market: implications for policy and planning. Hum Resour Health. 2012; 10:23. I Article | PubMed Abstract | PubMed FullText

4. Kang CM, Chiu HT, Hu YC, Chen HL, Lee PH and Chang WY. Comparisons of self-ratings on managerial competencies, research capability, time management, executive power, workload and work stress among nurse administrators. J Nurs Manag. 2012; 20:938-47. | Article I PubMed

5. Skytt B, Ljunggren B, Sjoden $P O$ and Carlsson $M$. The roles of the firstline nurse manager: perceptions from four perspectives. J Nurs Manag. 2008; 16:1012-20. | Article | PubMed

6. Westphal JA. Characteristics of nurse leaders in hospitals in the U.S.A. from 1992 to 2008. J Nurs Manag. 2012; 20:928-37. I Article I PubMed

7. Fagerstrom $L$ and Salmela $S$. Leading change: a challenge for leaders in Nordic health care. J Nurs Manag. 2010; 18:613-7. I Article I PubMed

8. Health Care Act (1326/2010). Ministry of Social Affairs and Health, Finland. | $\underline{\text { Pdf }}$

9. Hasselhorn H M, Conway P M, Widerszal-Bazyl M, Simon M, Tackenberg $\mathrm{P}$, Schmidt S, Camerino D and Muller B H. Contribution of job strain to nurses' consideration of leaving the profession - results from the longitudinal European nurses' early exit study. Scand J of Work, Environment and Health. 2008; 6:75-82.

10. Buick F, Blackman D A, O'Donnel M E, O'Flynn J L and West D. Can enhanced performance management support public sector change? J of Organizational Change Manag. 2015; 28:271-289. | Article 
Saarnio et al. Journal of Nursing 2016,

http://www.hoajonline.com/journals/pdf/2056-9157-3-2.pdf

11. Moran J W and Brightman B K. Leading organizational change. Career Development Internat. 2001; 6:111-118. I Article

12. Pardo-del-Val M, Martinez-Fuentes $C$ andRoig-Dobon S. Participative management and its influence on organizational change. Management Decision. 2012; 50:1843-1860. I Article

13. Chreim $S$, Williams $B E$, Janz $L$ and Dastmalchian $A$. Change agency in a primary health care context: the case of distributed leadership. Health Care Manage Rev. 2010; 35:187-99. I Article I PubMed

14. Bender M, Connelly CD and Brown C. Interdisciplinary collaboration: the role of the clinical nurse leader. J Nurs Manag. 2013; 21:165-74. | Article | PubMed

15. Nielsen K, Yarker J, Randall R and Munir F. The mediating effects of team and self-efficacy on the relationship between transformational leadership, and job satisfaction and psychological well-being in healthcare professionals: a cross-sectional questionnaire survey. Int J Nurs Stud. 2009; 46:1236-44. | Article | PubMed

16. Saarnio R, Vuoti M, Paasivaara L and Isola A. Hoitotyön johtajien tulevaisuudenkuvat sairaanhoitopiirinsä hoitotyön sisällöistä ja rakenteista. Premissi. 2012; 7:44-50.

17. Eskola J. The Method of Empathy-based Stories as a Method of Acquiring Data in Social Research. 1998.

18. Hyrkas K, Appelqvist-Schmidlechner K and Kivimaki K. First-line managers' views of the long-term effects of clinical supervision: how does clinical supervision support and develop leadership in health care? J Nurs Manag. 2005; 13:209-20. | Article I PubMed

19. Elo $\mathrm{S}$ and Kyngas $\mathrm{H}$. The qualitative content analysis process. J Adv Nurs. 2008; 62:107-15. | Article | PubMed

20. Denzin N K and Lincoln Y S. The SAGE handbook of qualitative research. $4^{\text {th }}$ edition. Thousand Oaks (California): Sage Publications. 2011.

21. National Advisory Board on Research Ethics. Good scientific practise and procedures for handling misconduct and fraud in science. 2003.

22. Lincoln Y S and Cuba E G. Naturalistic inquiry. Beverly Hills, California: Sage Publications. 1985.

23. Juntunen A and Saarti J. Library as the Student's Cornerstone or Obstacle: Evaluating the Method of Empathy-Based Stories. Libri. 2000; 50:235-240. | Article

24. Thylefors I. All professionals are equal but some professionals are more equal than others? Dominance, status and efficiency in Swedish interprofessional teams. Scand J Caring Sci. 2012; 26:505-12. | Article | PubMed

25. Kukkurainen ML, Suominen T, Rankinen S, Harkonen E and Kuokkanen L. Organizational vision: experience at the unit level. J Nurs Manag. 2012; 20:868-76. | Article | PubMed

26. Spence Laschinger HK, Wong CA, Grau AL, Read EA and Pineau Stam LM. The influence of leadership practices and empowerment on Canadian nurse manager outcomes. J Nurs Manag. 2012; 20:877-88. | Article | PubMed

27. Gantz NR, Sherman R, Jasper M, Choo CG, Herrin-Griffith D and Harris $\mathrm{K}$. Global nurse leader perspectives on health systems and workforce challenges. J Nurs Manag. 2012; 20:433-43. | Article I PubMed

\section{Citation:}

Saarnio R, Suhonen M and Isola A. Nurse managers' visions of future challenges in health care organizations. J Nurs. 2016; 3:2.

http://dx.doi.org/10.7243/2056-9157-3-2 